\title{
ПРАВОВАЯ ПРИРОДА РЕГУЛИРОВАНИЯ ОТНОШЕНИЙ МЕЖДУ СУБЪЕКТАМИ СИСТЕМЫ ЭЛЕКТРОЭНЕРГЕТИКИ В РОССИИ
}

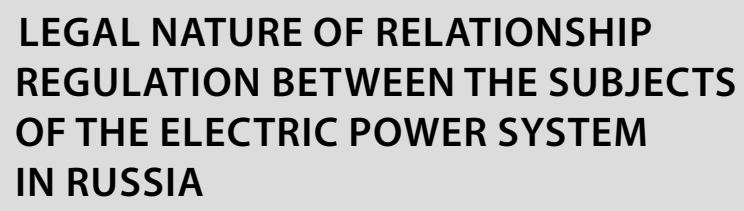

LEGAL NATURE OF RELATIONSHIP REGULATION BETWEEN THE SUBJECTS OF THE ELECTRIC POWER SYSTEM IN RUSSIA

\section{A. Manucharian}

Summary. This article presents the author's view of the legal nature of relations in the electric power industry. The necessity of developing productive and scientifically grounded approaches to this problematics at the integrative stage of the development of the legal system is substantiated. The position is argued that the modernization of the regulatory legal framework of the electric power industry is an inevitable phenomenon. And transformational changes and the application of new technological approaches in the functioning of the electric power industry require the improvement of private and public legal instruments of state regulation.

Keywords: electric power industry, energy law, state regulation, subjects of the electric power industry in Russia, methods of state regulation.

\author{
Манучарян Арсен Юрьевич \\ Аспирант, Российская академия народного \\ хозяйства и государственной службы при Президенте \\ Российской Федерации (РАНХиГС) \\ Arsen803366@gmail.com
}

Аннотация. В данной статье представлен авторский взгляд на правовую природу отношений в сфере электроэнергетики. 0боснована необходимость выработки продуктивных и научно-обоснованных подходов к данной проблематике на интегративном этапе развития системы права. Аргументировано положение, что модернизации нормативной правовой базы электроэнергетической отрасли является неизбежным явлением. А трансформационные изменения и применение новых технологических подходов при функционировании электроэнергетической отрасли требуют совершенствования частноправовых и публично-правовых инструментов государственного регулирования.

Ключевые слова: электроэнергетика, энергетическое право, государственное регулирование, субъекты системы электроэнергетики в России, методы государственного регулирования.
$\Pi$ равовая природа отношений, складывающихся между субъектами электроэнергетики, определяется исходя из той или иной деятельности, связанной с добычей, передачей или распределением электрической энергии. Субъектами электроэнергетики выступают генерирующие, электросетевые, сбытовые компании, органы исполнительной власти в области государственного регулирования цен (тарифов), а также организации, оказывающие содействие при функционировании электроэнергетической отрасли в целом. При этом, конечного потребителя электрической энергии также целесообразно рассматривать в качестве субъекта электроэнергетики, вне зависимости от того, к какой категории потребителей в соответствии с законодательством он относится. [1]

В соответствии с доктриной энергетического права, правовое регулирование отношений по производству, передаче и реализации электрической энергии входит в предмет энергетического права, в этой связи при квалификации правовой природы отношений между субъектами электроэнергетики детерминируется, что частноправовые отношения не являются исчерпывающими. При этом деятельность по генерации, передаче и сбыту электрической энергии (мощности) подлежит государственному регулированию, в этой связи, подобные правоотношения включают в себя и публично-правовые элементы отношений между соответствующими субъектами права.

К примеру, известный австралийский правовед А. Брэдбрук, придерживался опосредованного способа определения понятия энергетического права, с помощью понятий «энергетические ресурсы». [2] Данный подход позволял зафиксировать последовательность процесса от возникновения энергетических ресурсов до момента реализации энергии конечному потребителю, и в определение понятия энергетического права, по его мнению, входило «распределение прав и обязанностей, относящихся к разработке и использованию энергетических ресурсов между частными лицами и правительством, между правительствами и между государствами». [3]

Начиная от момента производства (генерации) электрической энергии, заканчивая использованием конечным потребителем энергоресурсов, формируется единый технологический процесс, целью которого 
является обеспечение безопасного, бесперебойного потребления электрической энергии конечным субъектом. [4]

Указанная специфика отношений подразумевает многосоставный характер электроэнергетической отрасли, предполагающий дифференцированный регуляторный подход со стороны государства, который проявляется в различных способах и формах государственного регулирования:

- метод прямого императивного воздействия;

- дискреционный метод.

В широком понимании метод прямого императивного воздействия проявляется в издании со стороны государства актов, непосредственно влияющих на формирование правоотношений между субъектами электроэнергетики. К ним в том числе относятся акты органов исполнительной власти в области государственного регулирования цен (тарифов) (также далее - регулирующие органы), формирующие систему ценовых ставок, по которым осуществляются расчеты за электрическую энергию (мощность), а также за услуги, оказываемые на оптовом и розничных рынках. Учитывая монопольный характер определенных видов деятельности в сфере электроэнергетики, цены (тарифы) регулируются путем издания предельных минимальных и максимальных уровней цен (тарифов), которые утверждаются ежегодно, например в отношении услуг по передаче электрической энергии по электрическим сетям. [5]

Дискреционный метод предусматривает распределение контрольных полномочий в отношении ряда вопросов, возникающих между субъектами электроэнергетики.

Данные полномочия реализуются посредством осуществления деятельности некоммерческих организаций, оказывающих сопровождение деятельности субъектов электроэнергетики на оптовом и розничных рынках электрической энергии (мощности). К подобным организациям, относится некоммерческое партнерство Совет рынка, в полномочия которых входит:

- организация системы досудебного урегулирования споров между субъектами оптового рынка и субъектами электроэнергетики в случаях, предусмотренных договором о присоединении к торговой системе оптового рынка; [6]

- установление системы и порядка применения имущественных и иных санкций в отношении субъектов оптового рынка;

- разработка мер, направленных на повышение платежной дисциплины на розничном рынке электроэнергии;
- осуществление контроля за соблюдением правил и регламентов оптового рынка субъектами оптового рынка - участниками обращения электрической энергии и (или) мощности, организациями коммерческой инфраструктуры, организацией по управлению единой национальной (общероссийской) электрической сетью

и и.д.

Комбинирование императивного и диспозитивного регуляторного подхода в первую очередь обусловлено особенностями, присущими деятельности по передаче электрической энергии, которая как ранее указывалось является монопольной. В широком понимании естественно монопольная деятельность по передаче электрической энергии характеризуется нецелесообразностью насыщения данного сектора отрасли конкуренцией, которая присуща, например деятельности по производству (генерации) электрической энергии. Экономически необоснованно дублировать линейные объекты, которые будут выполнять одинаковую функцию, в случае с передачей электрической энергии, такими объектами являются электрические сети, линии электропередачи.

При этом естественно монопольный вид деятельности и присущее ему государственное регулирования императивного воздействия на субъектов электроэнергетики, осуществляющих передачу электрической энергии по электросетям также связано и со стратегической безопасностью обеспечения помимо потребителей категории населения, и другой особой категорией «неотключаемых» потребителей. [7] К таким потребителям электрической энергии относят:

- органы государственной власти;

- медицинские учреждения;

- специальные объекты, находящиеся в ведении Министерства обороны Российской Федерации;

- объекты, участвующие при обращении и функционировании с ядерным топливом и материалами;

- объекты жилищно-коммунального хозяйства и т.д.

При этом, необходимо учитывать, что непосредственно деятельность по передаче электрической энергии за последние 10 лет претерпела значительные регуляционные трансформации, которые были обусловлены необходимостью выработки унифицированной государственной политики и последовательного воздействия при сочетании нескольких регуляторных подходов, с одной стороны обеспечивающих безопасность функционирования единой энергетической системы Российской Федерации, с другой стороны способствующих развитию конкурентной среды в тех областях электроэнергетической отрасли, где такая де- 
ятельность позволяет формировать развитый ценовой рынок электрической энергии.[8]

Таким образом, выстраивание отношений между субъектами электроэнергетики на основе сочетания императивного воздействия со стороны государства и диспозитивного метода дозволений, характеризует комплексность правовой природы данных правоотношений и в значительной степени предопределяет необходимость одновременного применения частноправового и публичного способа регулирования положения субъектов электроэнергетики на оптовом и розничных рынках электрической энергии (мощности).

Как ранее указывалось цены (тарифы) регулируются путем издания предельных минимальных и максимальных уровней цен (тарифов), при этом органом, уполномоченным осуществлять функции по тарифному регулированию на федеральном уровне является Федеральная антимонопольная служба, которой в соответствии с Указом Президента Российской Федерации переданы соответствующие полномочия упраздненной Федеральной службы по тарифам.[9]

Федеральная антимонопольная служба уполномочена осуществлять полномочия по утверждению цен (тарифов) на услуги по передаче электрической энергии и их предельные (минимальный и (или) максимальный) уровни, в том числе цены (тарифы) на услуги по передаче электрической энергии по единой национальной (общероссийской) электрической сети, предельные (минимальные и (или) максимальные) уровни цен (тарифов) на услуги по передаче электрической энергии по сетям, принадлежащим на праве собственности или ином законном основании территориальным сетевым организациям. Перечисленные функции относятся к так называемым полномочиям «ценового (тарифного) регулирования», при этом наряду с упомянутыми полномочиями, функции по выработке и реализации государственной политики и нормативно-правовому регулированию в сфере топливно-энергетического комплекса, в том числе по вопросам электроэнергетики относятся к компетенции Министерства энергетики Российской Федерации. Распределение контрольных полномочий между органами исполнительной власти Российской Федерации по регулированию отношений субъектов электроэнергетики способствует, координации различных нормативных подходов, в зависимости от технологических особенностей и структурной специфике субъектов, участвующих в деятельности по передаче электрической энергии.

Наряду с этим следует признать, что некоторые акты органов исполнительной власти, которые оказывают воздействия на правоотношения субъектов электроэнергетике, в некоторых ситуациях не являются нормативными правовыми актами, даже в тех случаях, когда воздействуют на неопределенный круг субъектов электроэнергетики. Например, приказ ФАС России от 20.04.2018 № 528/18 «Об отмене приказа Региональной энергетической комиссии Омской области «Об установлении единых (котловых) тарифов на услуги по передаче электрической энергии по сетям Омской области на 2018 год».

В судебной практике ранее уже встречались дела, связанные с определением признаков нормативности правового акта, а также разъяснения высших судебных инстанций по этому вопросу.

Существенные признаки, определяющие нормативный правовой акт, Верховный Суд Российской Федерации приводил в п. 9 Постановления Пленума от 29.11.2007 № 48 «О практике рассмотрения судами дел об оспаривании нормативных правовых актов полностью или в части», где перечислялись:

- издание акта в установленном порядке управомоченным органом государственной власти, органом местного самоуправления или должностным лицом;

- наличие в нем правовых норм (правил поведения), обязательных для неопределенного круга лиц и рассчитанных на неоднократное применение, направленных на урегулирование общественных отношений либо на изменение или прекращение существующих правоотношений.

При рассмотрении вышеуказанного приказа ФАС России, такой признак как неоднократность применения отсутствует, ввиду того, что приказ ФАС России от 20.04.2018 №528/18 «Об отмене приказа Региональной энергетической комиссии Омской области «Об установлении единых (котловых) тарифов на услуги по передаче электрической энергии по сетям Омской области на 2018 год» исчерпывается своим исполнением и не направлен на неоднократное применение.

Однако необходимо отметить, что Федеральная антимонопольная служба также наделена правом законодательной инициативы, которая реализуется путем издания нормативных правовых актов в области государственного регулирования цен (тарифов), оказывающих непосредственное воздействие на правоотношения субъектов электроэнергетики.

Приведенные правовые подходы регулирования в целом свидетельствуют о том, что отношения между субъектами электроэнергетики по своей правовой природе являются частью предмета энергетического права и при регулировании применяется сочетание частно- 
правового и публичного методов правового регулирования, при этом справедливо отметить, что различия в правовой квалификации отношений, складывающихся между субъектами электроэнергетики, нуждается в нормативной гармонизация законодательства, путем внесения содержательных изменений в Федеральный закон от 26.03.2003 № 35-Ф3 «О6 электроэнергетике» и Правила государственного регулирования (пересмотра, применения) цен (тарифов) в электроэнергетике, утвержденные постановлением Правительства Российской Федерации от 29.12.2011 № 1178, уточнив и раз- граничив понятие «нормативного (регулирующего) акта в области государственного регулирования цен (тарифов)».

Необходимость данных изменений законодательства в полной мере отражает потребность модернизации нормативной правовой базы данной сферы деятельности, которая в свою очередь обусловлена трансформационными изменениями и применением новых технологических подходов при функционировании электроэнергетической отрасли.

\section{ЛИТЕРАТУРА}

1. Приложение № 1 к Основам ценообразования в области регулируемых цен (тарифов) в электроэнергетике, утвержденным постановлением Правительства Российской Федерации от 29.12.2011 № 1178 // СЗ РФ. 2012. № 4. Ст. 504.

2. Городов 0.А. Введение в энергетическое право: учебное пособие. М.: Проспект, 2012. С. 7, 11

3. Указ Президента РФ от 21.07.2015 № 373 «0 некоторых вопросах государственного управления и контроля в сфере антимонопольного и тарифного регулирования» // СЗ РФ. 2015. № 30. Ст. 4571.

4. Пункт 5.3.21.5 постановления Правительства Российской Федерации от 30.06.2004 № 331 «06 утверждении Положения о Федеральной антимонопольной службе» // СЗ РФ. 2004. № 31. Ст. 3259.

5. Постановление Правительства РФ от 28.05 .2008 № 400 «0 Министерстве энергетики Российской Федерации».

6. Указанное определение приводится в статье 3 Федерального закона от 26.03.2003 № 35-Ф3 «06 электроэнергетике» при дефиниции понятия «цены (тарифы)» // СЗ РФ. 2003. № 13. ст. 1177.

7. Ц Цены (тарифы) и (или) их предельные уровни вводятся в действие с начала очередного года на срок не менее 12 месяцев. — пункт 7 Правил государственного регулирования (пересмотра, применения) цен (тарифов) в электроэнергетике, утвержденных постановлением Правительства Российской Федерации от 29.12.2011 № 1178 // СЗ РФ. 2012. № 4. Ст. 504.

8. Приказ ФАС России Приказ ФАС России от 26.11.2020 № 1162/20 «0б утверждении предельных минимальных и максимальных уровней тарифов на услуги по передаче электрической энергии, оказываемые потребителям, не относящимся к населению и приравненным к нему категориям потребителей, по субъектам Российской Федерации на 2021 год» // «0фициальный интернет-портал правовой информации» (www.pravo.gov.ru).

9. Bradbrook A. Energy Law as an Academic Discipline // Journal of Energy \& Natural Resources Law. 1996. Vol. 14. P. 194.

(с) Манучарян Арсен Юрьевич ( Arsen803366@gmail.com ).

Журнал «Современная наука: актуальные проблемы теории и практики» 